\title{
A More Rapid, Sensitive, and Specific HPLC-MS/MS Method for Nifedipine Analysis in Human Plasma and Application to a Pharmacokinetic Study
}

Authors

Affiliations

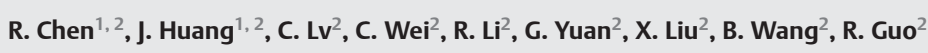

${ }^{1}$ The Institute of Pharmacology, Medical Faculty of Shandong University, Jinan, China

${ }^{2}$ The Institute of Clinical Pharmacology, Qilu Hospital of Shandong University, Jinan, China
Key word

- nifedipine

- HPLC-MS/MS

- pharmacokinetics

- acetaminophen

received 06.09.2012 accepted 26.11.2012

Bibliography

DOI http://dx.doi.org/

10.1055/s-0032-1331713

Published online:

January 23, 2013

Drug Res 2013;

63: 38-45

(c) Georg Thieme Verlag KG

Stuttgart - New York

ISSN 2194-9379

Correspondence

R. Guo

Institute of Clinical

Pharmacology

Qilu Hospital of Shandong

University

107 West Wenhua Road

jinan 250012

People's Republic of China

Tel.: + 86/531/82169636

Fax: + 86/531/8610 9975

grc7636@126.com

\section{Abstract}

$\nabla$

A more rapid, sensitive and specific high-performance liquid chromatography coupled to tandem mass spectrometry (HPLC-MS/MS) was developed and validated for the quantification of nifedipine in human plasma, and applied to the pharmacokinetic study of nifedipine in Chinese healthy volunteers. Nifedipine and internal standard (IS) acetaminophen in plasma were extracted with ethyl acetate, separated on a $\mathrm{C}_{18}$ $(150 \mathrm{~mm} \times 4.6 \mathrm{~mm}, 5 \mu \mathrm{m})$ reversed-phase column, eluted with acetonitrile mixed with $5 \mathrm{mM}$ ammonium acetate solution $(\mathrm{pH}=6.62)(60: 40$, $\mathrm{v} / \mathrm{v}$ ), ionized by negative ion pneumatically assisted electrospray and detected in the multireaction monitoring mode using precursor $\rightarrow$ product ions of $\mathrm{m} / \mathrm{z} 354.1 \rightarrow 222.2$ for nifedipine and $150.1 \rightarrow 107.1$ for the IS. A single oral dose of $20 \mathrm{mg}$ nifedipine sustained release tablets and blood samples $(4 \mathrm{~mL})$ was collected before and 1 ,

\section{Abbreviations \\ $\nabla$ \\ LLE liquid-liquid extraction \\ MRM multiple reaction monitoring \\ SPE solid-phase extraction}

\section{Introduction}

$\nabla$

Nifedipine, 1, 4-Dihydro-2, 6-dimethyl-4-(2nitrophenyl)-3, 5-pyridinedicarboxylic acid dimethyl ester ( $\bullet$ Fig. 1a), is a dihydropyridine calcium channel blocker and can be used for treatment of hypertension, angina pectoris and other vascular disorders. Through physically plugging the channel and resulting in decreases of intracellular calcium levels, inhibiting of the contraction processes of smooth muscle cells, dilate the coronary and systemic arteries, increase oxygen delivery to the myocardial tis-
$2,2.5,3,3.5,4,4.5,5,6,8,12,24$, and $36 \mathrm{~h}$ after administration. The main pharmacokinetic parameters of nifedipine, as $\mathrm{T}_{\max }, \mathrm{t}_{1 / 2 \alpha}, \mathrm{t}_{1 / 2 \beta}, \mathrm{t}_{1 / 2 \mathrm{z}}$, $\mathrm{C}_{\max }, \quad \mathrm{AUC}_{0 \sim 36}, \quad \mathrm{AUC}_{0 \sim \infty}$ were $2.80 \pm 0.50 \mathrm{~h}$, $6.78 \pm 2.52 \mathrm{~h}, \quad 6.82 \pm 2.53 \mathrm{~h}, \quad 6.69 \pm 2.22 \mathrm{~h}$, $76.69 \pm 19.51(\mathrm{ng} / \mathrm{mL}), 546.49 \pm 162.28(\mathrm{ng} \cdot \mathrm{h} / \mathrm{mL})$ and $564.05 \pm 176.74(\mathrm{ng} \cdot \mathrm{h} / \mathrm{mL})$, respectively. The calibration curve was linear over the concentration range of $0.17-102 \mathrm{ng} / \mathrm{mL}\left(r^{2}>0.99, n=5\right)$ with a lower limit of quantification (LLOQ) of $0.17 \mathrm{ng} / \mathrm{mL}$. The intra- and inter-day precision was less than $15 \%$ for all quality control samples at concentrations of $0.42,6.53$ and $81.60 \mathrm{ng} / \mathrm{mL}$ and the accuracy (relative error, RE) was $-3.92 \%$ to $7.31 \%$ at 3 quality control levels. The specificity, matrix effect, recovery, sensitivity, linearity, accuracy, precision and stabilities were validated, and can fulfill the requirement of pharmacokinetic study of nifedipine sustained release tablets in Chinese volunteers. sue, decrease total peripheral resistance and systemic blood pressure [1].

Numerous analytical methods included gas chromatography (GC), liquid chromatography (LC) and high performance liquid chromatography (HPLC) have been reported for the determination of nifedipine in biological samples. GC methods often utilize electron-capture detection, flame ionization detection, nitrogen-phosphorus detection, or mass spectrometric (MS) detection [2-4] to provide high sensitivity for nifedipine pharmacokinetic studies, but the method has several drawbacks, including its thermal decomposition under GC condition and time-consuming. LC methods without coupling with MS detection $[5,6]$ were also time-consuming in sample disposition. Furthermore, the linearity range from $10-200 \mathrm{ng} / \mathrm{mL}$ did not fulfill the requirement for a much low limit of quantitation (LLOQ) of nifedipine pharmacokinetic studies. While the LC/MS 




Fig. 1 The chemical structure of nifedipine $\mathbf{a}$ and acetaminophen $\mathbf{b}$.

Table 1 Optimized mass spectrometry parameters for nifedipine and IS.

\begin{tabular}{|c|c|c|c|c|}
\hline Analyte & $\begin{array}{l}\text { precursor| } \\
\text { productions }\end{array}$ & $\begin{array}{l}\text { Fragment } \\
\text { electric voltage }\end{array}$ & $\begin{array}{l}\text { collision } \\
\text { energy }(\mathrm{eV})\end{array}$ & EMV \\
\hline nifedipine & $345.1 / 222.2$ & 100 & 5 & 400 \\
\hline $\begin{array}{l}\text { acetami- } \\
\text { nophen }\end{array}$ & $150.1 / 107.1$ & 100 & 20 & 400 \\
\hline
\end{tabular}

method based on electrospray ionization (ESI) or atmospheric pressure chemical ionization (APCI) [7-9] provided an LLOQ of $1.0 \mathrm{ng} / \mathrm{mL}$, each run need a relative long time $(8 \mathrm{~min})$ and large volume of plasma samples $(1.0 \mathrm{~mL})$. UPLC-MS/MS, with short retain time and much lower limit of quantification [10], is expensive and not available in many clinical laboratories. The high performance liquid chromatography-tandem mass spectrometry (HPLC-MS/ MS) method developed in this study is simple, rapid, selective, has high sensitivity and high sample throughput relative to other methods. Several publications have reported about HPLC-MS/MS method, as deproteinized with methanol and the calibration curves over the range of $0.5-50 \mathrm{ng} / \mathrm{mL}$ [11] as liquid-liquid extraction with the LLOQ of $1 \mathrm{ng} / \mathrm{mL}$ [12], did not meet the requirements for sensitivity of nifedipine determination in plasma for human pharmacokinetic studies.

Sample pretreatment has also been an item of interest for the analysis of nifedipine in biological samples. Previous methods included solid-phase extraction (SPE), protein precipitation and Liquid-liquid extraction (LLE). On-line SPE is expensive and complex, especially for a large number of samples [13]. After protein precipitation, the samples remained impure and were with the risk of blocking and poor response [14]. A liquid-liquid extraction (LLE) method with ether: n-hexane (3:1, v/v)[15], diethyl ether [12] and cyano cartridges were conditioned successively with $2 \mathrm{ml}$ of methanol, $2 \mathrm{ml}$ of Milli-Q water and $2 \mathrm{ml}$ of $0.01 \%$ phosphoric acid [16] have been reported, but these reagents are toxic or expensive. A simpler, less toxic, faster and more economical method allowing for a reduction of sample manipulation and total analysis time was required.

A faster, sensitive, simple and less toxic HPLC-MS/MS approach based on the LLE with ethyl acetate as the extraction solvent, is more cost-effective, validated and can be used for the determination of nifedipine in plasma and for pharmacokinetic studies.

\section{Experimental \\ $\nabla$}

\section{Chemicals and reagents}

Nifedipine (Lot: 100338-200502, purity: 99.8\%) and acetaminophen (Lot: 10018-0107, purity: 99.8\%) were obtained from National institute for the Control of Pharmaceutical and Biological Products, Beijing China. Methanol (Lot: K32E12) and ace- tonitrile (Lot: H30754) were HPLC grade from J. T. BAKER, USA. Ethyl acetate (Lot: H39B05, HPLC grade) was obtained from Sinopharm Chemical Reagent Co. LTD. Ammonium acetate (Lot: 10133751, Analytical) was obtained from the company of A Jonson Mattery. Blood plasma (Lot: 20110926) was obtained from Qilu Hospital of Shandong University. Purified water (Lot: 20120310) was obtained from the Company of Wahaha.

\section{HPLC/MS/MS instrumentation and chromatographic conditions}

The HPLC-MS/MS procedure was performed using an Agilent 1200 series HPLC and an Agilent 6410 Triple Quadrupole mass spectrometer equipped with an electrospray ionization source (Agilent Technologies, USA). All data were analyzed by software Agilent 6410 Quantitative Analysis version analyst data processing software.

The chromatographic separation was achieved on a Diamond $C_{18}$ column $(150 \mathrm{~mm} \times 4.6 \mathrm{~mm}, 5 \mu \mathrm{m}$, Dikma Technologies, Beijing, china) at $25^{\circ} \mathrm{C}$ with a thermostated column oven. The mobile phase was acetonitrile mixed with $5 \mathrm{mM}$ ammonium acetate solution $(\mathrm{pH}=6.62)(60: 40, \mathrm{v} / \mathrm{v})$, with a thermostated flow rate of $0.8 \mathrm{~mL} / \mathrm{min}$. The injection volume was $10 \mu \mathrm{L}$.

Mass spectrometric analysis was performed in the negative ion MRM mode, with spray gas pressure (350 Pa), protective air of nitrogen gas $9.0 \mathrm{~L} / \mathrm{min}$, dwell times $(200 \mathrm{~ms})$, and capillary voltage $(4000 \mathrm{v})$. The fragment electric voltage, collision energy and quantification of nifedipine and IS (acetaminophen) were achieved by monitoring the $\mathrm{m} / \mathrm{z}$ of precursor/product ions ( $\bullet$ Table 1). Calculations were based on peak area radios of analyte to internal standard. Concentrations are interpolated from a linear least squares regression and calibration curve was based on $1 /$ concentration $^{2}$ weighting for both analytes.

The column was washed with a 95:5 water-acetonitrile (v/v) mobile phase for $50 \mathrm{~min}$ and then with acetonitrile for $50 \mathrm{~min}$ when every batch was finished.

Preparation of calibration standards, internal standard, and quality controls

Nifedipine is a photo labile compound, and a nitroso-pyridine derivative is formed in solution on exposure to visible light, while a nitro-pyridine derivative is generated under ultraviolet light [17]. Therefore, the whole process of the experiment must be operated in dark place.

A $10.2 \mathrm{mg}$ aliquot of nifedipine standard and a $10.1 \mathrm{mg}$ aliquot of acetaminophen were weighed in an analytical balance and transferred to $2 \mathrm{~A}$-grade $10 \mathrm{~mL}$ volumetric flasks, dissolved with methanol to obtain nifedipine $(1.02 \mathrm{mg} / \mathrm{mL})$ and $\mathrm{IS}(1.01 \mathrm{mg} / \mathrm{mL})$ mother solutions. Primary stock solutions were diluted with the mobile phase for standard working solutions of nifedipine (102, $10.20,1.02 \mu \mathrm{g} / \mathrm{mL}$ ) and IS was dissolved with mobile phase to get a $1010 \mathrm{ng} / \mathrm{mL}$ stock solution. All solutions were stored at $4{ }^{\circ} \mathrm{C}$ and dark places, and equilibrated to room temperature before use (approximately $15 \mathrm{~min}$ ).

The calibration curve standard and quality control (QC) samples were freshly prepared with blank plasma by spiking with different working solutions. The calibration samples consist of eight nonzero concentrations (0.17 102 ng/mL), and QC samples were 0.17(LLOQ), 0.42(LQC) and 6.53(MQC), $81.60 \mathrm{ng} / \mathrm{mL}$ (HQC) for nifedipine.

\section{Plasma pre-treatment}

The aim of sample pre-treatment method should remove interferences from the biological sample and also be reproducible with a high recovery and simple procedure involving a mini- 
mum number of working steps and less cost. A liquid-liquid extraction method was used for the extraction of nifedipine and IS from plasma. $50 \mu \mathrm{L}$ of IS (1010 $\mathrm{ng} / \mathrm{mL}$ acetaminophen) was mixed with $500 \mu \mathrm{L}$ plasma sample, then $3.5 \mathrm{~mL}$ ethyl acetate was added, vortex-mixed for $2 \mathrm{~min}$, and centrifuged at $5000 \mathrm{rpm}$ for $5 \mathrm{~min}$ (2266g). $3 \mathrm{~mL}$ organic phase was transferred to a clean tube and evaporated to dryness under gentle stream of nitrogen gas at $35^{\circ} \mathrm{C}$. Residue was reconstituted with $100 \mu \mathrm{L}$ mobile phase, and $10 \mu \mathrm{L}$ was injected onto the HPLC-MS/MS for analysis.

\section{Method Validation}

$\nabla$

The assays of nifedipine in human plasma were validated in compliance with the US Food and Drug Administration [18] and Chinese State Food and Drug Administration guidelines for the validation of bioanalytical methods including assay selectivity, linearity, recovery, matrix effects, accuracy, precision and stability.

\section{Selectivity}

The specificity of the method was evaluated by comparing chromatograms of 6 different lots of blank human plasma to identify the potential interference of endogenous substances at the HPLC peak region (nifedipine and IS).

\section{Calibration curves}

Calibration curves were prepared at 8 different nifedipine concentrations. Each calibration standard was injected in 5 replicates. Calibration curves were typically described by equation $\mathrm{y}=\mathrm{ax}+\mathrm{b}$, where $\mathrm{y}$ represents the peak-area ratio of nifedipine to IS, and $x$ represents the plasma concentration of nifedipine. The linearity of the calibration curves was assessed by linear regression with a weighting factor of the reciprocal of the concentration squared $\left(1 / \mathrm{x}^{2}\right)$. The calibrators for analytes were: $0.17,0.42$, $1.04,2.61,6.53,16.32,40.80$ and $102 \mathrm{ng} / \mathrm{mL}$.

The low limit of quantification (LLOQ) was defined as a signalto-noise ratio greater than 10 and evaluated by analyzing 5 replicates of spiked plasma samples at the concentration of 0.17 . The acceptance criterion for each back-calculated standard concentration was $\pm 15 \%$ deviation from the nominal value, while that of LLOQ was $\pm 20 \%$.

\section{Recovery and matrix effect}

The mean overall recovery of the nifedipine was determined by comparing the peak areas (extracted plasma standards/post extraction plasma samples). Nifedipine were determined by samples at $3 \mathrm{QC}$ levels $(0.42 \mathrm{ng} / \mathrm{mL}$ as low, $6.53 \mathrm{ng} / \mathrm{mL}$ as medium and $81.60 \mathrm{ng} / \mathrm{mL}$ as high) with 5 replicates for each QC level. The recovery of the IS $(101 \mathrm{ng} / \mathrm{mL})$ was determined in a similar way. Matrix effect was investigated to ensure selectivity, precision and sensitivity that were not compromised by the matrix screened. Blank plasma samples were extracted and spiked with the nifedipine at $3 \mathrm{QC}$ levels and IS in 5 replicates. The corresponding peak areas were compared to those of standard solutions, and the peak area ratio was defined as the matrix effect.

\section{Precision and accuracy}

The intra-assay precision and accuracy were estimated by analyzing 5 replicates of nifedipine at 3 different QC levels $(0.42 \mathrm{ng} /$ $\mathrm{mL}, 6.53 \mathrm{ng} / \mathrm{mL}$ and $81.60 \mathrm{ng} / \mathrm{mL}$ ) in human plasma. The interassay precision was determined by analyzing the 3-level QC samples on 3 consecutive days. The criteria for acceptability of data were accuracy within $85 \%$ 115\% from the nominal values and a precision of within $\pm 15 \%$ relative standard deviation (RSD) or CV\%, but that of LQC is not supposed to exceed $\pm 20 \%$.

\section{Stability}

The stability of each analyte in plasma was determined by 3 QC levels in 5 replicates. the stabilities of nifedipine in plasma samples at different concentration were examined under different study conditions, including that the post-extracted samples in the HPLC auto-samples at room temperature $\left(25^{\circ} \mathrm{C}\right)$ for $0 \mathrm{~h}$ (fresh samples) and $7 \mathrm{~h}$, the stability of analytes in human plasma with three QC levels were stored at $-20^{\circ} \mathrm{C}$ for 7 and 60 days and the stability of analytes in human plasma following two freeze-thaw cycles and three freeze-thaw cycles. The samples were processed as described above and the criterion for acceptability of the data is the same with that for the precision and accuracy.

\section{Pharmacokinetic study}

20 healthy Chinese male volunteers were involved and all provided written informed consent. Exclusion criteria included the physical examination and laboratory tests when they were unqualified; a history of cardiovascular, hepatic, renal, psychiatric, neurologic, hematologic, or metabolic disease; drug or alcohol abuse within 2 years before the start of the study; allergic constitution; smoking, a history of drug allergy; had severe low blood volume, orthostatic hypotension, arrhythmias, asthma, and a history of glaucoma, sitting heart rate was less than 60 beats/min; consumption of any prescribed or over-the-counter drugs within 2 weeks before the study; or participation in a similar study within the past 6 months. The protocol was approved by the Ethics committee of the College of Medicine, Shandong University, Jinan, China, and the study was conducted in accordance with the declaration of Helsinki and Chinese Good Clinical Practice guidelines.

Demographic characteristics of 20 Chinese male volunteers (mean (SD) for the overall group included age, 25.39(1.32) years (range from 23 to 28); weight, 67.06 (8.10) $\mathrm{kg}$ (rang from 56 to $80 \mathrm{~kg}$ ); height, 1.74 (0.06) m (rang from 162 to 185); and BMI, 22.15 (1.71) (rang from 20.20 to 24.98) ( $\bullet$ Table 2). No volunteer was withdrawn from the pharmacokinetic study.

A single oral dose of either test or reference of $20 \mathrm{mg}$ nifedipine sustained release tablets with $200 \mathrm{~mL}$ of water were given at 7:00, and blood samples $(4 \mathrm{~mL})$ were collected before and 1,2 , $2.5,3,3.5,4,4.5,5,6,8,12,24$, and $36 \mathrm{~h}$ after administration into sodium heparin $(20: 1)$ containing tubes, centrifuged at $5000 \mathrm{rpm}$ for $5 \mathrm{~min}(2266 \mathrm{~g})$ and plasma subsequently quoted into plastic tubes and stored at $-20^{\circ} \mathrm{C}$ for analysis.

\begin{tabular}{|llllll} 
Nominal concentration $(\mathbf{n g} / \mathbf{m L})$ & Actual concentration $\left(\mathbf{n g} \cdot \mathbf{m L}^{-1}\right)$ & Mean & SD & RSD(\%) & RE(\%) \\
& 0.18 & & & & \\
& 0.15 & & & & \\
0.17 & 0.18 & 0.16 & 0.01 & 8.4 & -3.5 \\
& 0.16 & & & &
\end{tabular}

Table 2 The analyte response at the LLOQ in human plasma $(n=5)$. 




Fig. 2 chromatograms of a blank plasma, $\mathbf{b}$ standard solution of nifedipine and IS, c blank plasma spiked with nifedipine $(32.65 \mathrm{ng} / \mathrm{mL})$ and $\mathrm{IS}$, d plasma sample of subject NO. 8 after $3 \mathrm{~h}$ of oral administration in period 1 .

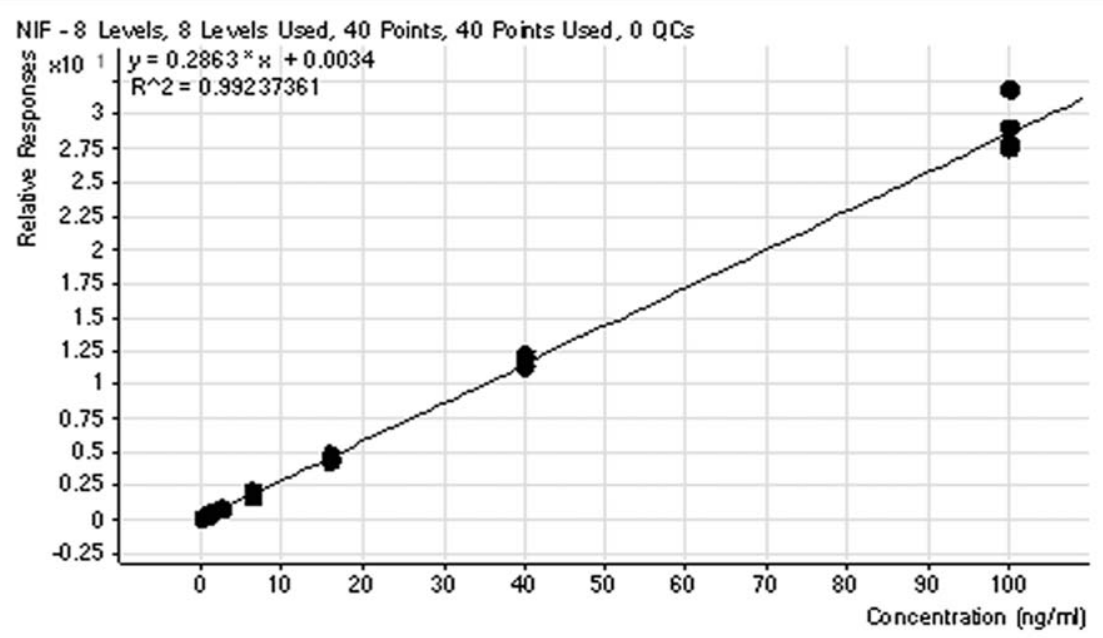

Fig. 3 The graph showing the coefficient of correlation of nifedipine samples $(n=40)$ that every calibration curves has eight concentration levels analyzed by HPLC/MS/MS.
Drug and Statistic software (DAS 2.0, P. R. of China) was used to fit the compartmental model of nifedipine in human and to calculate its main pharmacokinetic parameters.

\section{Results}

$\nabla$

\section{Method validation}

Selectivity

The interference by endogenous plasma constituents with analytes and IS was assessed by inspection of chromatograms that included typical MRM chromatograms of blank plasma, nifedipine and IS standard, blank plasma spiked with nifedipine and IS, and plasma from a volunteer after administration of nifedipine sustained release tablets ( $\bullet$ Fig. 2 ), retention time of nifed-
Table 3 Matrix effect and extraction recovery of nifedipine and IS in human plasma $(n=5)$.

\begin{tabular}{|cclll|}
\hline \multirow{2}{*}{$\begin{array}{l}\text { Nominal } \\
\text { concentration }\end{array}$} & \multicolumn{2}{c}{ Matrix effect } & \multicolumn{2}{c|}{ Extraction recovery } \\
(ng/mL) & Mean \pm SD & RSD & Mean \pm SD & RSD \\
\hline 0.42 & $93.06 \pm 6.02$ & 6.47 & $78.05 \pm 2.32$ & 2.97 \\
\hline 6.53 & $95.07 \pm 6.18$ & 6.50 & $79.61 \pm 4.38$ & 5.50 \\
\hline 81.60 & $100.57 \pm 5.73$ & 5.70 & $82.88 \pm 6.03$ & 7.28 \\
\hline $101($ IS $)$ & $98.30 \pm 5.65$ & 5.74 & $78.77 \pm 6.67$ & 8.47 \\
\hline
\end{tabular}

ipine and IS were 3.65 and $2.25 \mathrm{~min}$, respectively, and no significant interferences were found at the retention times of the analytes and IS. 


\begin{tabular}{|cclcccc} 
Nominal & \multicolumn{3}{c}{ intraday(n=5) } & \multicolumn{3}{c}{ interday(n=15) } \\
concentration (ng/mL) & Mean \pm SD (ng/mL) & RSD (\%) & RE (\%) & Mean \pm SD (ng/mL) & RSD (\%) & RE (\%) \\
\hline 0.42 & $0.41 \pm 0.03$ & 6.94 & -2.97 & $0.40 \pm 0.02$ & 5.38 & -3.92 \\
\hline 6.53 & $6.15 \pm 0.23$ & 3.74 & -1.68 & $6.19 \pm 0.29$ & 4.69 & -1.11 \\
81.60 & $83.23 \pm 3.86$ & 4.63 & 1.99 & $87.57 \pm 3.83$ & 4.37 & 7.31 \\
\hline
\end{tabular}

Table 4 Intraday and interday precision and accuracy for analysis of nifedipine in human plasma.

\section{Calibration curve and LLOQ}

A calibration curve was established ranging from 0.17 to $102 \mathrm{ng} /$ $\mathrm{mL}$ nifedipine in plasma. The calibration curves were regressed using a quadratic equation with a weighting factor of $1 / \mathrm{x}^{2}$. The coefficient of correlation of all calibration curves were more than $0.99(\mathrm{n}=5)(\odot$ Fig. 3).

The LLOQ was defined as the lowest concentration on the standard calibration curves with acceptable repeatability and recovery. The analyte response at the LLOQ was should be at least 5 times the response of blank baseline. The LLOQ was evaluated by analyzing five replicates of spiked plasma samples at the concentration of $0.17 \mathrm{ng} / \mathrm{mL}$ for each analyte. The precision (RSD\%) and accuracy (RE\%) were found to be $8.4 \%$ and $-3.5 \%$ in $\odot$ Table 2 .

\section{Recovery and matrix effect}

The extraction recoveries of nifedipine were $78.05 \pm 2.32$, $79.61 \pm 4.38$ and $82.88 \pm 6.03$ at the concentrations of $0.42,6.53$ and $81.60 \mathrm{ng} / \mathrm{mL}$, respectively $(\mathrm{n}=5)$, and IS was $78.77 \pm 6.67$ $(101 \mathrm{ng} / \mathrm{mL}, \mathrm{n}=5)$. The recoveries of nifedipine and IS were similar and the data proved that the liquid-liquid extraction method was sufficient and was not concentration-dependent. The matrix effect is a matter of notorious fact in electrospray ionization mass spectrometry, which will influence the analyte ionization by signal enhancement or suppression. To reduce the matrix effect, the extraction solvent and compositions and ratio of mobile phase were investigated for finding optimal outcome. The matrix effect was $93.06 \pm 6.02,95.07 \pm 6.18$ and $100.57 \pm 5.73$ for nifedipine at the concentrations of $0.42,6.53$ and $81.60 \mathrm{ng} /$ $\mathrm{mL}$, respectively $(\mathrm{n}=5)$, and $98.30 \pm 5.65$ for IS $(n=5)$, suggesting that there was no significant matrix effect in this procedure ( $\bullet$ Table 3). These indicated that the analytical method could be kept free endogenous substances in human plasma.

\section{Accuracy and precision}

The intra-day and inter-day precision and accuracy data for nifedipine in plasma is summarized in $\odot$ Table 4, and they were assessed by the determining of QC samples with 5 replicates for each concentration level on the same day or on 3 consecutive days. Precision was expressed by coefficient of variation (RSD) and accuracy by relative error (RE), and accuracy was expressed by mean and standard deviation (SD). The assay values on both the occasions (intra-day and inter-day) were found to be within the accepted variable limits.

\section{Stability studies}

Stability for nifedipine after $0 \mathrm{~h}$ and $7 \mathrm{~h}$ in autosampleris were shown in 0 Table 5a, 2 freeze-thaw cycles and 3 freeze-thaw cycles were shown in $\odot$ Table $5 \mathbf{b}$, and freezed at $-20^{\circ} \mathrm{C}$ for 7 and 60 days were shown in $\odot$ Table $\mathbf{5 c}$. The results indicated that the analytes were stable at ambient temperature for $0 \mathrm{~h}$ and $7 \mathrm{~h}$ after post extracted, at $-20^{\circ} \mathrm{C}$ for 7 and 60 days, and for 2 and 3 cycles of freezing and thawing. The data conform to the acceptance criteria.
Table 5a The stability of post-extracted samples in the HPLC auto-samples at room temperature $\left(25^{\circ} \mathrm{C}\right)$ for $0 \mathrm{~h}$ and $7 \mathrm{~h}$. $(n=5)$.

\begin{tabular}{|lcrlr} 
condition & $\begin{array}{l}\text { Nominal } \\
\text { concentration } \\
(\mathbf{n g} / \mathrm{mL})\end{array}$ & $\begin{array}{l}\text { Mean } \pm \text { SD } \\
(\%)\end{array}$ & $\begin{array}{l}\text { RSD } \\
(\%)\end{array}$ & \multicolumn{1}{c}{$\begin{array}{l}\text { RE } \\
(\%)\end{array}$} \\
fresh & 0.42 & $0.43 \pm 0.03$ & 7.09 & 3.87 \\
sample(0h) & 6.53 & $7.13 \pm 0.13$ & 1.78 & 11.33 \\
\hline post- & 81.60 & $85.94 \pm 5.51$ & 6.41 & 7.42 \\
extracted & 0.42 & $0.46 \pm 0.02$ & 4.91 & 11.38 \\
sample(7h) & 6.53 & $7.01 \pm 0.16$ & 2.28 & 9.52 \\
& 81.60 & $89.90 \pm 1.45$ & 1.67 & 8.63 \\
\hline
\end{tabular}

Table $\mathbf{5 b}$ The stability of nifedipine in human plasma following two freezethaw cycles and three freeze-thaw cycles. $(n=5)$.

\begin{tabular}{|lcclc|} 
condition & $\begin{array}{c}\text { Nominal concen- } \\
\text { tration }(\mathbf{n g} / \mathbf{m L})\end{array}$ & $\begin{array}{l}\text { Mean } \pm \text { SD } \\
(\%)\end{array}$ & $\begin{array}{l}\text { RSD } \\
\mathbf{( \% )}\end{array}$ & $\begin{array}{c}\text { RE } \\
\mathbf{( \% )}\end{array}$ \\
\hline two freeze- & 0.42 & $0.40 \pm 0.02$ & 4.93 & -2.34 \\
thaw cycles & 6.53 & $6.31 \pm 0.25$ & 3.91 & -1.4 \\
\hline & 81.60 & $85.09 \pm 4.67$ & 5.48 & 6.37 \\
\hline three & 0.42 & $0.42 \pm 0.03$ & 6.13 & 0.48 \\
freeze- & 6.53 & $6.44 \pm 0.37$ & 5.73 & -1.44 \\
thaw cycles & 81.60 & $82.65 \pm 2.76$ & 3.33 & 1.29 \\
\hline
\end{tabular}

Table 5c The stability of nifedipine in human plasma with three QC levels at $-20^{\circ} \mathrm{C}$ for 7 and 60 days $(n=5)$.

\begin{tabular}{|lcclc|} 
condition & $\begin{array}{l}\text { Nominal concen- } \\
\text { tration }(\mathbf{n g} / \mathbf{m L})\end{array}$ & $\begin{array}{l}\text { Mean } \pm \text { SD } \\
(\%)\end{array}$ & $\begin{array}{l}\text { RSD } \\
\text { (\%) }\end{array}$ & \multicolumn{1}{c|}{$\begin{array}{c}\text { RE } \\
(\%)\end{array}$} \\
\hline$-20^{\circ} \mathrm{C}$, & 0.42 & $0.38 \pm 0.01$ & 2.97 & -7.81 \\
\hline 7 days & 6.53 & $6.51 \pm 0.27$ & 4.15 & 1.64 \\
& 81.60 & $78.41 \pm 7.42$ & 9.46 & -1.99 \\
\hline$-20^{\circ} \mathrm{C}$, & 0.42 & $0.37 \pm 0.03$ & 8.72 & -9.86 \\
60 days & 6.53 & $6.50 \pm 0.52$ & 8.02 & 1.49 \\
\hline
\end{tabular}

\section{Clinical application}

The validated method was applied to a pharmacokinetic study for determination of nifedipine concentration in human plasma after a single oral dose of its sustained release tablets. A $1 / \mathrm{C}$ weighted coefficients regression analysis and 2-compartmental model were used to fit the disposition of nifedipine in Chinese volunteers. The mean concentration-time curve is shown in $\odot$ Fig. 4. The main pharmacokinetic parameters are shown in $\triangle$ Table 6 . The results were found to be within the assay variability limits during the entire process.

\section{Discussion}

$\nabla$

\section{Mass spectrometry optimization}

In order to optimize ESI conditions for nifedipine and IS, both the positive and negative ion modes were investigated. However, 


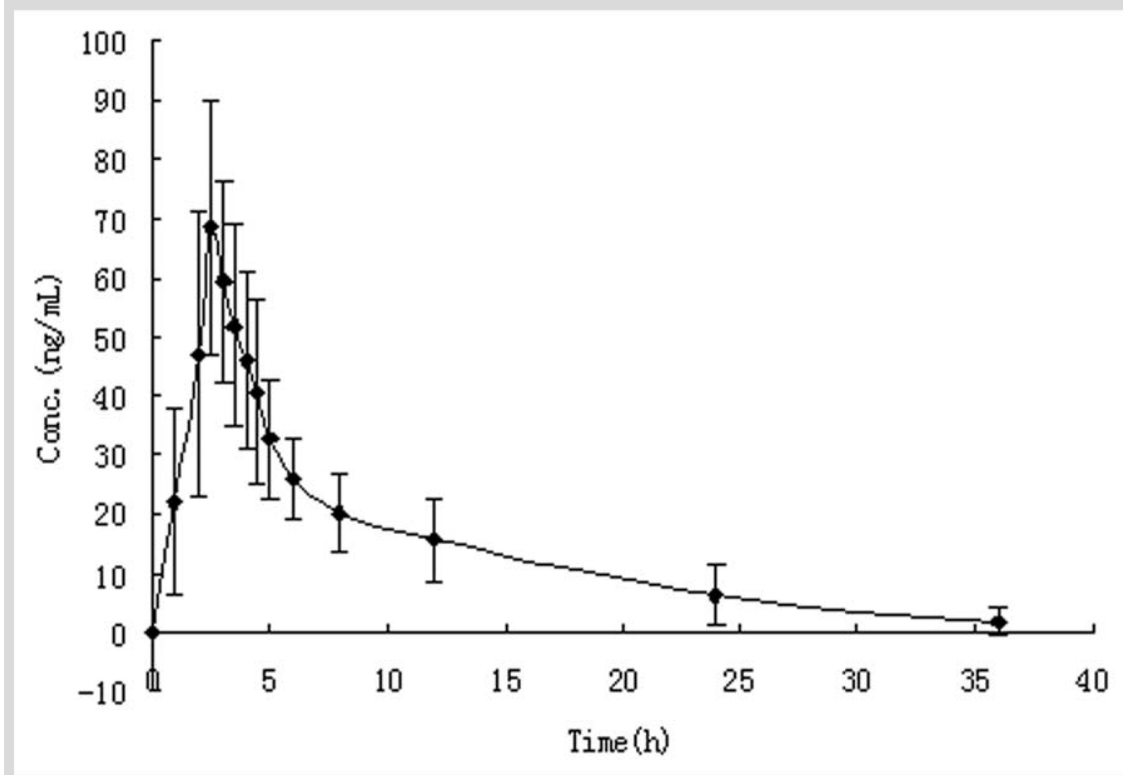

Fig. 4 Mean plasma concentration-time curve of nifedipine after oral administration of $20 \mathrm{mg}$ nifedipine sustained-release tablet $(n=20)$.

a poor linearity in positive ionization condition and a good response was found in negative ionization mode. The solutions containing nifedipine and IS were injected directly into the mass spectrometer. Under these conditions, the analytes yielded major ions at m/z 345.1 for nifedipine and m/z 150.1 for IS. Each of precursor ions was subjected to collision-induced dissociation to determine the resulting product ions. The full-scan negative product ion mass spectra of precursor ion spectrum of nifedipine and IS and the product ion mass spectra of nifedipine and IS are shown in $\bullet$ Fig. 5 . The results showed that the most sensitive and abundant mass transitions were $\mathrm{m} / \mathrm{z} 345.1 \rightarrow 222.2$ for nifedipine and $150.1 \rightarrow 107.1$ for IS. The MRM state file parameters were the optimized values for the sensitivity and specificity required for nifedipine.

\section{Selection of IS}

It was difficult to find a compound that could ideally mirror the analyte to serve as a suitable IS that should mimic the analyte during extraction and have a stationary response, especially, for HPLC-MS/MS, matrix effect used to induce poor analytical. Several compounds were investigated, such as nitrendipine, diazepam, hydrochlorothiazide, glycyrrhetinic acid and acetaminophen. Nitrendipine had long retention time, diazepam was no peak under the negative ion detection mode, hydrochlorothiazide had serious smear under the conditions used and glycyrrhetinic did not proper product ion under product scan mode. None of these, but finally acetaminophen ( $\bullet$ Fig. 1b) was found to be the most appropriate for the present purpose. The retention time of acetaminophen was short to that of nifedipine. Chromatograms were obtained and no significant direct interference in the MRM channels at the relevant retention time was observed and it could save time for a large samples analysis.

\section{Sample pre-treatment}

Protein precipitation, Liquid-liquid extraction (LLE) and solid phase extraction (SPE) were tested and compared, with acetonitrile, toluene, and ether-n-hexane $(3: 1, v / v)$ as protein precipitation solvents, but protein precipitation was easy to dilute the sample and failed to sufficiently remove endogenous interference. SPE had too many disturbances to good reproducibility and recovery $[16,19]$. What is more, the column for SPE is expen-
Table 6 Main pharmacokinetic parameters of nifedipine after administration of $20 \mathrm{mg}$ nifedipine sustained-release tablets $(n=20$, Mean \pm SD).

\begin{tabular}{|lc}
\hline Parameter & Value \\
$\mathrm{AUC}_{(0-36)}(\mathrm{ng} \cdot \mathrm{h} / \mathrm{mL})$ & $546.49 \pm 162.28$ \\
$\mathrm{AUC}_{(0-\infty)}(\mathrm{ng} \cdot \mathrm{h} / \mathrm{mL})$ & $564.05 \pm 176.74$ \\
$\mathrm{MRT}_{(0-36)}(\mathrm{h})$ & $8.40 \pm 1.60$ \\
\hline $\mathrm{MRT}_{(0-\infty)}(\mathrm{h})$ & $9.42 \pm 2.66$ \\
\hline $\mathrm{CL}(\mathrm{L} / \mathrm{h} / \mathrm{kg})$ & $0.03 \pm 0.01$ \\
\hline $\mathrm{CLz}(\mathrm{L} / \mathrm{h} / \mathrm{kg})$ & $0.04 \pm 0.02$ \\
$\mathrm{Vz}(\mathrm{L} / \mathrm{kg})$ & $0.37 \pm 0.17$ \\
\hline $\mathrm{C}_{\max }(\mathrm{ng} / \mathrm{mL})$ & $76.69 \pm 19.51$ \\
\hline $\mathrm{T}_{\max }(\mathrm{h})$ & $2.80 \pm 0.50$ \\
\hline $\mathrm{t}_{1 / 2 \alpha}(\mathrm{h})$ & $6.78 \pm 2.52$ \\
$\mathrm{t}_{1 / 2 \beta}(\mathrm{h})$ & $6.82 \pm 2.53$ \\
\hline $\mathrm{t}_{1 / 2 z}(\mathrm{~h})$ & $6.69 \pm 2.22$ \\
\hline $\mathrm{K}_{10}(1 / \mathrm{h})$ & $0.11 \pm 0.04$ \\
\hline $\mathrm{K}_{12}(1 / \mathrm{h})$ & $0.03 \pm 0.04$ \\
\hline $\mathrm{K}_{21}(1 / \mathrm{h})$ & $0.12 \pm 0.04$ \\
\hline $\mathrm{VRT}_{(0-36)}\left(\mathrm{h}^{2}\right)$ & $55.22 \pm 18.42$ \\
\hline $\mathrm{VRT}_{(0-\infty)}\left(\mathrm{h}^{2}\right)$ & $96.21 \pm 72.60$ \\
\hline
\end{tabular}

sive and not suitable for high-throughput analysis when a large number of samples were processed. LLE was used for producing chromatographia clean samples in the study, which contributed to minimizing ion suppression and matrix effects in HPLC-MS/ MS. LLE with various extraction solvents, including diethyl ether, chloroform, dichloromethane and ethyl acetate, were investigated and evaluated for acceptable extraction recoveries and matrix effect. Diethyl ether, extraction recoveries were about $42.12 \%$ and unacceptable, chloroform was easy to emulsify when the sample was made vortex and mixed and its recover was about $54.20 \%$, dichloromethane, matrix effect were about $75.23 \%$ and disturb the results. Ethyl acetate was with several obviously advantages, firstly, the upper organic phase was transferred easily, secondly, ethyl acetate possesses less toxicity, good stability and repeatability, finally, extraction recoveries were approximately $81.63 \%$ ( $\bullet$ Table 7 ). Furthermore, it was also tested whether sodium hydroxide $(0.05 \mathrm{~mol} / \mathrm{L})$ was added to extraction solvents, and there were not obvious difference for peak area and retention time. 


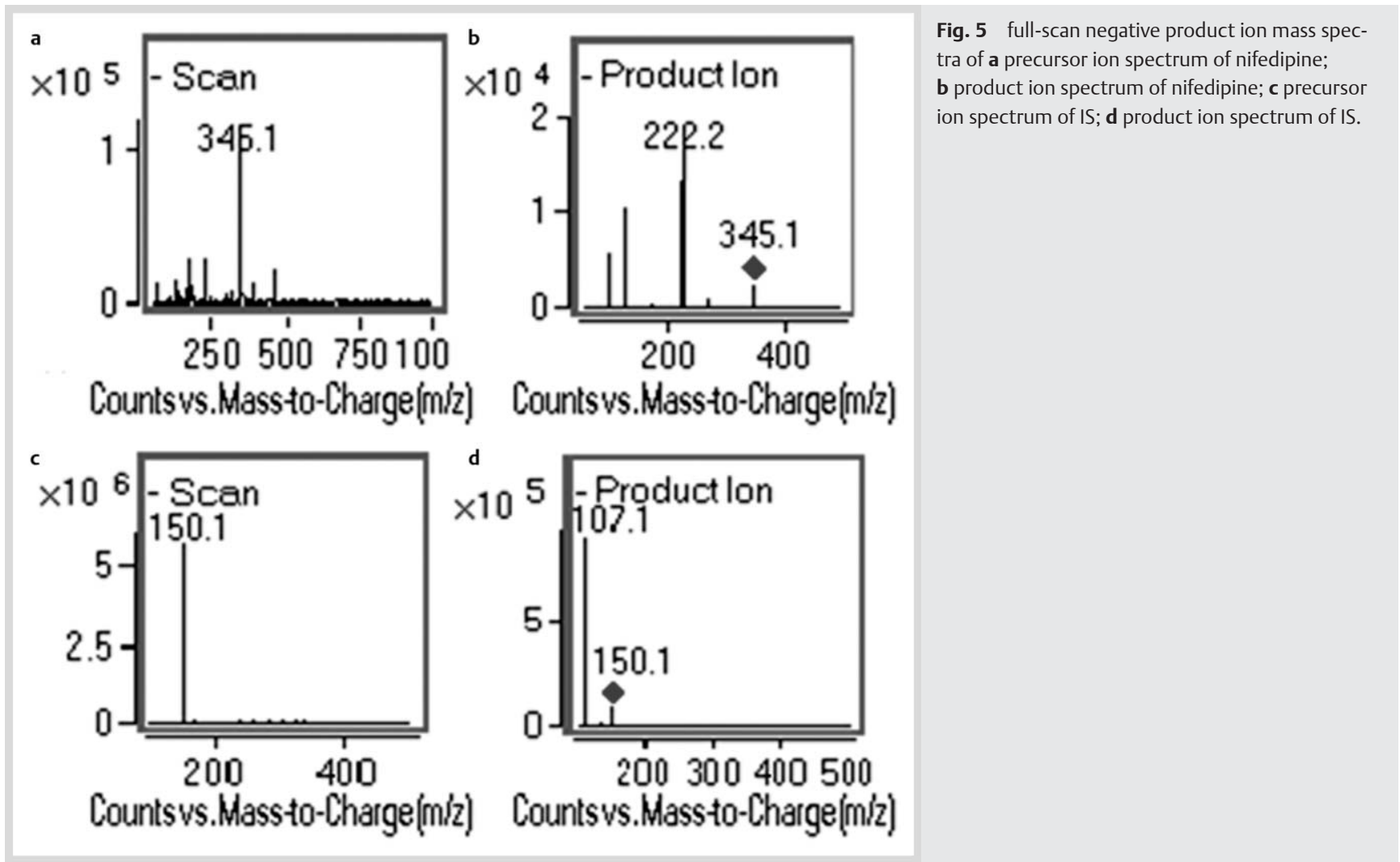

Solvents included methanol, acetonitrile, $5 \mathrm{mmol} / \mathrm{L}$ ammonium acetate and mobile phase for reconstituting residues were also investigated to optimize the chromatographic behaviors for optimizing peak shape and minimum peak response. Mobile phase with good peak shape and minimum response was adopted.

\section{Liquid chromatography}

A simple chromatographic separation was developed for acquisition of good separation with a short run time. The feasibility of various mixtures of solvents such as acetonitrile and methanol using different water phase, including $5 \mathrm{mM}$ ammonium acetate ( $\mathrm{pH}=6.62), 2 \mathrm{mM}$ ammonium acetate $(\mathrm{pH}=7.19)$, water and $1 \%$ methanoic acid were tested, along with altered flow-rates (in the range of $0.5-1 \mathrm{~mL} / \mathrm{min}$ ), was tested to identify the optimal mobile phase that produced the best sensitivity, efficiency and peak shape. It was found that acetonitrile mixed with $5 \mathrm{mM}$ ammonium acetate solution $(\mathrm{pH}=6.62)(60: 40, \mathrm{v} / \mathrm{v})$ could achieve this purpose in negative ionization mode and finally used as the mobile phase. A flow rate of $0.8 \mathrm{~mL} / \mathrm{min}$ permitted a run time of $5 \mathrm{~min}$.

\section{Conclusions}

In summary, a highly sensitive, specific, reproducible and highthroughput HPLC-MS/MS method that we developed and validated based on the procedure of LLE for determination of nifedipine with IS. The procedure was fully validated to meet the requirements for sensitivity, accuracy and precision from State Food and Drug Administration and GLP Guidelines for industry. According to the validation parameters, the developed method
Table 7 The development summary of liquid-liquid extraction procedure (20ng/mL, n=5).

\begin{tabular}{llllr} 
extraction & Matrix effect & & \multicolumn{2}{c}{ Extraction recovery } \\
solvent & Mean \pm SD & RSD & Mean \pm SD & RSD \\
& (\%) & (\%) & (\%) & (\%) \\
diethyl ether & $71.53 \pm 9.63$ & 11.32 & $42.12 \pm 5.76$ & 19.77 \\
chloroform & $68.11 \pm 2.11$ & 10.97 & $54.20 \pm 6.89$ & 8.15 \\
\hline dichloromethane & $75.23 \pm 5.22$ & 14.33 & $68.42 \pm 8.71$ & 17.88 \\
\hline ethyl acetate & $97.56 \pm 5.12$ & 5.40 & $81.63 \pm 5.10$ & 4.32 \\
\hline
\end{tabular}

could be useful for nifedipine pharmacokinetic studies and routine therapeutic drug monitoring with desired precision and accuracy.

\section{Acknowledgements}

The authors thank Huanghai Pharmaceutical (Shandong) Co. Ltd, China, for providing financial support. Project supported by the Major National Science And Technology Project (2012ZX09303016-003)

\section{Conflict of Interest}

$\nabla$

The authors declare no conflict of interest.

References

1 Hamann SR, Piascik MT, McAllister RG. Aspects of clinical pharmacology of nifedipine, a dihydropyridine calcium-entry antagonist. Biopharmaceutics and Drug Disposition 1986; 7: 1-10

2 Higuchi S, Shiobara Y. Quantitative determination of nifedipine in human plasma by selected ion monitoring. Biological Mass Spectrometry 1978; 3: 220-223 
3 Wu J, Zhang ZX, Wang $Y$ et al. Determination of nifedipine in human plasma by gas chromatography and its pharmacokinetics study. Acta Pharmacologic Sinica 1997; 32: 147-150

4 Lutz D, Llias E, Jaeger $H$. Automated determination of nifedipine in human plasma by capillary gas chromatography with electron capture detection. Journal of High Resolution Chromatography 1986; 7: $397-399$

5 Yritia M, Parra P, Iglesias E et al. Quantitation of nifedipine in human plasma by online solid-phase extraction and high-performance liquid chromatography. Journal of Chromatography A 2000; 870: 115-119

6 Abou-Auda HS, Najjar TA, Al-Khamis KI et al. Liquid chromatographic assay of nifedipine in human plasma and its application to pharmacokinetic studies. Journal of Pharmaceutical and Biomedical Analysis 2000; 22: 241-249

$7 \mathrm{Ma} A L$, Lian JW, Bi KS et al. Determination of nifedipine in human plasma by HPLC-MS and its application to pharmacokinetics study. China Hospital Pharmacology Journal 2008; 28: 2013-2015

8 Chen $X$, Zhong $D$, Yang $H$ et al. Quantitative determination of nitrendipine and its metabolite dehydronitrendipine in human plasma using liquid chromatography $\square$ tandem mass spectrometry. Biomedical Chromatography 2001; 15: 518-524

9 Guo Y, Dai J, Qian G et al. Determination of nifedipine in human plasma and its use in bioequivalence study. International Journal of Pharmaceutics 2007; 341: 91-96

10 Dan W, Kun J, Shuyan $Y$ et al. determination of nifedipine in human plasma by ultra performance liquid chromatography-tandem mass spectrometry and its application in a pharmacokinetic study. Journal of Chromatography B 2011; 879: 1827-1832

11 Hua S, Xianghong $L$ et al. Determination of nifedipine in human serum by HPLC-MS/MS. Zhongguo Yaolixue Tongbao 2010; 26: 1516-1519

12 Yunzhen $G$, Jinna $D$, Guiling $Q$ et al. Determination of nifedipine in human plasma and its use in bioequivalence study. International Journal of Pharmaceutics 2007; 341: 91-96
13 Yritia M, Parra P, Iglesias E et al. Quantitation of nifedipine in human plasma by on-line solid-phase extraction and high-performance liquid chromatography. Journal of Chromatography A 2000; 870: 115-119

14 Yueping Z, Ying C, Yanrong $Z$ et al. Pharmacokinetics properties and bioequiavailability of nifedipine sustained-release tablets after multiple doses administration in heathy volunteer. J Fourth Mil Med Univ 2009; 30: 761-763

15 Xueding $W$, Jiali $L$, Yan $L$ et al. Rapid and simultaneous determination of nifedipine and dehydronifedipine in human plasma by liquid chromatography-tandem mass spectrometry: Application to a clinical herb-drug interaction study. Journal of Chromatography B 2007; 825: 534-544

16 Ioannis $N$, Athanasios $C D$. Determination of nifedipine in human plasma by solid-phase extraction and high-performance liquid chromatography: validation and application to pharmacokinetic studies. Journal of Pharmaceutical and Biomedical Analysis 2003; 32: 1213-1218

17 Walley TJ, Heagerty AM, Woods KL et al. Pharmacokinetics and pharmacodynamics of nifedipine infusion in normal volunteers. British Journal of Clinical Pharmacology 1987; 23: 693-710

18 Viswanathan C, Bansal S, Booth B et al. Quantitative bioanalytical methods validation and implementation: best practices for chromatographic and ligand binding assays. Pharmaceutical Research 2007; 24: 1962-1973

19 Li ZP, Zhong MK, Shi XJ et al. A solid phase extracted-HPLC method for determining nifedipine in human plasma. Chinese Journal Clinical Pharmacology 2005; 14: 115-117 